\title{
Person-to-person interactions in online classroom settings under the impact of COVID-19: a social presence theory perspective
}

\author{
Tai-ming Wut ${ }^{1} \oplus$. Jing $X^{1}$
}

Received: 20 August 2020 / Revised: 12 January 2021 / Accepted: 19 January 2021 / Published online: 4 February 2021

(c) Education Research Institute, Seoul National University, Seoul, Korea 2021

\begin{abstract}
The COVID-19 pandemic has compelled universities and higher education institutions to largely adopt online teaching to avoid face-to-face interactions. Instructors and students teach and learn through computers, laptops, and mobile phones with Internet connections. This qualitative study conducted in-depth interviews with 17 university students and 7 instructors. It found that student-to-instructor and student-to-student interactions cannot fully establish cognitive social presence and affective social presence. It then provided recommendations including encouragement, incentives, breakout rooms, and engagement techniques.
\end{abstract}

Keywords Social presence theory $\cdot$ Student-to-instructor interactions $\cdot$ Student-to-student interactions $\cdot$ Online learning $\cdot$ COVID-19

\section{Introduction}

The past year has seen many countries suffer from the spread of COVID-19. Businesses and government departments have had to cease operations or take alternative operational modes to maintain a minimum level of business activity owing to such a force majeure. Schools and universities, meanwhile, have been severely affected by the pandemic. Universities and higher education institutions needed to shift from traditional classroom teaching to online teaching to avoid face-to-face interactions. Instructors and students adopted technology such as digital tools, computers, laptops, and mobile phones with Internet connections, which poses new challenges for both. Universities and instructors have to adapt and immediately shift to such a new lifestyle and, at the same time, find ways to fulfil learning objectives and outcomes and ensure good teaching quality.

Research focus on online education and teaching has increased because of the worldwide spread of COVID19 , for instance, in the contexts of mainland China (Bao

Tai-ming Wut

Edmund.wut@cpce-polyu.edu.hk

1 College of Professional and Continuing Education, The Hong Kong Polytechnic University, PolyU West Kowloon Campus, 9 Hoi Ting Road, Yau Ma Tei, Kowloon, Hong Kong
2020; Zhang et al. 2020), Georgia (Basilaia and Kvavadze 2020), the United States (Hodges et al. 2020; Iyer et al. 2020), and other countries (Sobaih et al. 2020; Toquero 2020). The majority of these studies have conducted case studies, among other methods, to determine the pandemic's impacts on education and discuss its implications in terms of responsive strategies and recommending guidelines. In fact, because the shift from traditional to online education with the support of digital technology has been largely recognized as a trend or a forecast mainstream in the near future (Sobaih et al. 2020; Palvia et al. 2018), the long-term environment requires a better understanding of online education with effective preparation and better technological prowess. Some studies (e.g., Goh and Sandars 2020) have noted that a return to the prepandemic education approach would be unlikely, as the ongoing change is transformative in nature.

Having been cognizant of these needs, this paper discusses the lessons derived from online teaching through a case study research context. Specifically, the current study examines the relevant phenomena and challenges focusing on the interactions among people involved in online teaching, that is, instructors and students. Studies have highlighted that the lack of person-to-person interactions threatens the quality of online education (Popovich and Neel 2005). Nevertheless, a consolidation of instructors' and students' views from a teaching and learning perspective, respectively, may 
be academically and practically significant. Thus, this study aims to answer the following research questions:

(1) What are the possible challenges to student-to-instructor and student-to-student interactions in online learning under the influence of COVID-19?

(2) What possible measures can be adopted to facilitate student-to-instructor and student-to-student interactions in online learning under the influence of COVID-19?

\section{Background}

\section{Coronavirus outbreak}

In early December 2019, pneumonia cases of an unknown source were identified at Huanan Seafood Wholesale Market in Wuhan, the capital city of Hubei province in China. The most notable clinical symptoms of infected individuals were dry cough, dyspnea, fever, and bilateral lung infiltrates on X-rays (Sohrabi et al. 2020). Given the clustered outbreak and the presence of asymptomatic patients and "superspreaders," the "2019 novel coronavirus," which the World Health Organization (WHO) called "COVID-19," spread rapidly throughout Mainland China on January 30, 2020 (Sohrabi et al. 2020). Following the virus's worldwide transmission, the WHO subsequently declared a Public Health Emergency of International Concern. COVID-19 became a severe worldwide pandemic, with a total of $12,964,809$ confirmed cases globally including 570,288 deaths as of July 14, 2020 (WHO 2020). Reported figures by continent showed America as the worst-hit country, with 6,780,428 cases and 288,430 deaths, followed by European countries, with 2,946,104 and 203,957, respectively (WHO 2020). To deal with this long-term public health emergency with much uncertainty in its risks and impacts, the WHO Information Network for Epidemics (EPI-WIN) highlighted the urgent need to manage such uncertainty via communication and engagement of communities (WHO 2020).

Since COVID-19 can stay aloft for hours in tiny droplets in stagnant air, which infect people as they inhale, crowded indoor spaces with poor ventilation pose a high risk (Morawska and Cao 2020). Virus-laden particles are also transmitted via larger droplets expelled when a sick person coughs or sneezes or when one is in contact with contaminated surfaces, which led to the recommendation of frequent hand-washing and maintaining at least a 1-m distance (Morawska and Cao 2020). As air travel has become a strongly relevant risk factor for the spread of the virus, at the end of January 2020, some countries such as Italy started suspending visa issuances and flights from China and other highly infected countries (Lau et al. 2020). Under the deteriorating conditions, worldwide travel restrictions included tourist bans, on-site disease detection, and temporary passenger quarantine, which usually took 2 weeks (Salcedo et al. 2020).

By January 7, 2020, a total of 59 COVID-19 cases have been reported in Wuhan, with 21 suspected cases in Hong Kong. However, that month also saw the resumption of schools and universities in Hong Kong. As originally planned, college students returned to school on January 20. On January 25, they celebrated the Chinese Lunar New Year; on the same day, the Hong Kong government declared an Emergency Response Level under its Preparedness and Response Plan for Novel Infectious Disease of Public Health Significance. This led to the closing of all schools and universities after the holiday. Online classes were then proposed as a temporary solution that would run for 5 weeks, but were subsequently prolonged until May 2020 to cover the whole semester (Crawford et al. 2020). As schools were forced to be closed for infection control, teachers and students resorted to online technologies such as video conferencing and educational apps (Hodges et al. 2020). However, research conducted among students after the school holidays has identified nonschool factors as a primary source of inequality in educational outcomes between children from lower and higher socioeconomic backgrounds, which include a widening gap in mathematical and literacy skills (Van Lancker and Parolin 2020). Those from lower income households are likely to experience homeschooling difficulties because of problems finding suitable places to complete homework and connect to the Internet to attend online courses as well as the long-lasting effects to children's health, well-being, and learning outcomes brought by the severe economic recession (Van Lancker and Parolin 2020).

Students' study patterns might have also been disrupted during the COVID-19 outbreak. More take-home assignments were arranged, and students had to work continuously throughout the semester. However, students in fact got used to focusing on their studies only right before tests and final examinations (Gonzalez et al. 2020) before the pandemic. To address and facilitate such a change, several important research themes were proposed: online delivery of teaching materials, teacher support for students' online study, and online participation in student learning (Bao 2020). Thus, the relevant research agenda would include the two types of person-to-person interaction: student-toinstructor and student-to-student.

Some universities such as Cambridge University will conduct all their lectures online until the summer of 2021 . Most universities will be online or in hybrid mode for the entire 2020-2021 academic year. This means that under the influence of COVID-19, online learning has become a new "normal" part of college life. 


\section{Literature review}

\section{Social presence theory}

Online learning systems provide tools that allow students and teachers to flexibly exchange viewpoints. However, the quality of such communication could be affected by social presence (Chang and Hsu 2016). Face-to-face discussions are usually more effective than electronic means (Gefen and Straub 2004), and social presence could particularly influence information-sharing behavior. The social presence construct has three dimensions: awareness, cognitive social presence, and affective social presence (Shen and Khalifa 2008). First, building one's online presence is extremely important, and awareness might increase personal interactions (Chang and Hus 2016). Second, online participants can use the e-platform to explore available information, solve their problems, and find answers based on student-to-instructor and student-to-student interactions (Shen and Khalifa 2008, p. 730). Students can easily establish common understanding through shared dialog. Finally, affective social presence refers to students' level of emotional connection through online interactions (Shen and Khalifa 2008). Affective social presence has been proven to facilitate information exchange (Shen et al. 2010). The remoteness of online learning has made it difficult to know how online participants feel until they have shared interactive and positive responses.

\section{Online education and challenges}

Online education has been increasingly adopted because of ongoing technological development and the corresponding research attention (Palvia et al. 2018). Studies have summarized the associated benefits, challenges, and issues surrounding online education (e.g., Li and Beverly 2008; Maguire 2005). Benefits include the accessibility and affordability of online teaching (Li and Beverly 2008). However, institutions and instructors need to exercise caution in designing their teaching methods; this could be a challenging task (Ni 2018). Maguire (2005) identified a variety of motivators as well as inhibitors to online education. Motivators are classified into three levels, intrinsic, extrinsic, and institutional, while inhibitors mainly focus on intrinsic and institutional considerations. As such, some faculty members wanted to use technology to facilitate teaching, while others were more reluctant to make such attempts (intrinsic level). On the other hand, some instructors preferred consulting with other colleagues and peers for decision-making and advice (extrinsic level). In addition, the consideration of online teaching would considerably depend on the available resources of schools and institutions, including administrative, technical, and technological support. These would either motivate or inhibit the teaching staff from adopting online education (institutional level). A further concern is whether to associate online education with the performance appraisal of teaching staff. In this study, because of the pandemic, all faculty members needed to make immediate changes and professional transitions, and institutions were forced to immediately transfer financial and manpower resources to support online education.

More specific operational disadvantages and challenges to online education included "potentially reduced quality of education, increased faculty training costs, faculty resistance, financial aid constraints, employers' bias against online degrees, lack of appropriateness for all subjects/course content, increased cost of technological update, program startup costs and challenges, potentially reduced student/professor interactions, irrelevance of previous location advantage, and potential infringement on existing programmes" (Popovich and Neel 2005, quoted in Palvia et al. 2018, p. 236). Studentto-instructor interaction has been notably highlighted in a straightforward manner. In another study, Hrastinski (2008, p. 1760) reiterated that many learners or students are more passive, and are inclined to participate, contribute, and communicate in writing; correspondingly, instructors would use mainly asynchronous discussion forums to "judge" students' participation. Some students may also attribute their participation and interactions to Internet-related barriers such as inadequate hardware and software, slow connections, and lack of training and orientation support (Nkonge and Gueldenzoph 2006). Instructors also face difficulties such as student procrastination, lack of technical expertise, and additional time required to design online courses (Keengwe and Kidd 2010). However, the "emergency remote teaching" caused by the epidemic has been quite rushed and has lacked good planning and effective resource management, which may worsen the situation (Hodges et al. 2020). A systematic review of sustainable online education is thus imperative.

\section{Person-to-person interaction}

The importance of students' interactions with their instructors and peers has been constantly recognized by existing education and distance education literature (Bernard et al. 2009; Moore 1989). Interaction activities take place between at least two individuals. In classroom settings, such exchanges can be divided into student-to-instructor and student-to-student interactions (Moore 1989). Outside the classroom, other interactions could occur between instructors (Anderson 2003). Interactions can also be observed between students and subject learning content (Moore 1989). Similar to face-to-face classrooms, online classroom 
platforms also allow for different types of two-way communication, which significantly influences learning (Holden and Westfall 2006).

Students' interactions with their instructors are unquestionably important. For example, students expect timely feedback from instructors after they post questions or topics for discussion online (Weaver and Albion 2005). Quality feedback and responses from teachers have been long recognized as equally important for both traditional and online education (Coll et al. 2014). Studies have established the significance of student-to-instructor interactions on the extent of student satisfaction and teaching quality (Bolliger and Martindale 2004; Kuo et al. 2014). On one hand, online platforms may provide students convenience and variety when interacting with their instructors. For instance, Bernard et al. (2009) indicated that features such as e-mail, videoconferencing, chatrooms, and discussion forums/boards on online platforms motivate interaction. On the other hand, online classrooms do not operate as smoothly as expected because of several barriers to the stimulation and maintenance of this type of interaction. Specifically, students may feel reluctant to raise questions or provide feedback to instructors in online classroom settings, which may alter the effectiveness of learning outcomes; they may also feel embarrassed to showcase their "social presence" and identity on online platforms (Gunawardena and Zittle 1997). In addition, instructors also face difficulties in conduct classes using online platforms, and they may behave differently as opposed to how they would in the traditional classrooms (Swan 2002). Specifically, instructors' sense of humor and ability to lead the class emotionally may diminish in online learning spaces (Swan 2002).

The literature has also highlighted the differences between student interactions in the traditional and online classrooms (Abrami et al. 2011). For instance, exchanges among students can be either synchronous or asynchronous (Bernard et al. 2009). They expect their peers, classmates, or friends to contribute to their learning experiences. This will also be an important motivator for students to participate in interactions with others (Weaver and Albion 2005). Thus, learning outcomes are closely associated with intense communication and discussion among students (Picciano 1998). Gunawardena and Zittle (1997) demonstrated the effect of "social presence" and students' relationships on student satisfaction through online learning. Thus, student-to-student interaction is also crucial to strategic online education and virtual classroom management, which continues to be a research gap.

Comparing student-to-instructor and student-to-student interactions, some studies on online education have found that the latter are more important particularly when required by instructors while conducting class (e.g., Jung et al. 2002). For instance, students need to work together on group projects or assessments to fulfil the course requirements. However, another relevant study (Kuo et al. 2014) found that student satisfaction cannot be successfully regressed to student-to-student interactions as opposed to student-toinstructor interactions. Such findings may vary according to the nature and requirements of a specific course, and thus, student-to-student interactions cannot be ignored particularly when they involve certain collaborative learning activities and constitute part of course requirements (Jung et al. 2002). Such research definitely necessitates more empirical evidence.

\section{Method}

This study adopted an in-depth interview approach, which is commonly used to elicit research participants' views on research questions. According to Kumar (2005), in-depth interviews are considered repeated personal interactions between the researcher and informants in an attempt to understand the latter's thoughts as expressed in their own words. Building confidence and increasing understanding between interviewer and interviewee could lead to the collection of rich and accurate information. In-depth interviews may involve asking a student to imagine a situation in which they are using an e-learning platform. However, it is also important to realize that asking interviewees different questions might affect their thought processes and perceptions. Researchers, meanwhile, must also be aware that they may interpret some interviewee data subjectively. Neither the interviewer nor their subjects can be separated entirely from the research process and outcomes. The Hawthorne effect may also be present, where researchers' perceived expectations and physical presence sometimes direct respondents' behaviors subconsciously.

In this study, in-depth interviews with university students and instructors were conducted in Hong Kong. The authors started this process in March 2020 and applied for ethical approval. After obtaining approval from the college, the authors sent invitations to instructors and students in April 2020. Participation was completely voluntary, and all participants provided informed consent. Because the traditional examinations were replaced by additional take-home assignments because of the epidemic, the respondents' schedules became limited. Some of the students and instructors who had expressed their interest in participating in this study requested to quit. Hence, a total of 24 research participants (17 students and 7 instructors) participated in this study through face-to-face or online format within the research period (i.e., May 2020). The interviews were conducted in Chinese, but were recorded and translated into English by a professional editor (Table 1). 
Table 1 Basic Information of respondents

\begin{tabular}{|c|c|c|c|}
\hline Instructor & Gender & Disciplines & Teaching experience \\
\hline Teacher1 & Female & Business/Marketing & 10 years \\
\hline Teacher2 & Female & Business/Marketing & 10 years \\
\hline Teacher3 & Female & Business/Marketing & 10 years \\
\hline Teacher4 & Female & Language & $5-10$ years \\
\hline Teacher5 & Female & Social Science & $5-10$ years \\
\hline Teacher6 & Male & Business/Marketing & 10 years \\
\hline Teacher7 & Male & Science & $5-10$ years \\
\hline Student & Gender & Disciplines & Year \\
\hline Student1 & Female & Business/Marketing & 4 \\
\hline Student2 & Female & Business/Marketing & 4 \\
\hline Student3 & Female & Business/Marketing & 4 \\
\hline Student4 & Female & Business/Marketing & 4 \\
\hline Student5 & Female & Business/Marketing & 4 \\
\hline Student6 & Female & Business/Marketing & 4 \\
\hline Student7 & Female & Business/Marketing & 4 \\
\hline Student8 & Female & Business/Marketing & 4 \\
\hline Student9 & Female & Business/Marketing & 4 \\
\hline Student10 & Female & Social Science & 4 \\
\hline Student11 & Female & Business/Marketing & 4 \\
\hline Student 12 & Female & Business/Marketing & 4 \\
\hline Student13 & Male & Applied Science & 4 \\
\hline Student14 & Male & Arts & 4 \\
\hline Student15 & Male & Business/Marketing & 4 \\
\hline Student16 & Male & Business/Marketing & 4 \\
\hline Student17 & Male & Business/Marketing & 4 \\
\hline
\end{tabular}

There were two male and five female instructors; four of them taught business or marketing management, one language, one social science, and one natural science. Five of them have been teaching for more than 10 years. As for the student participants, 5 were male and 12 were female. At the time of the study, $60 \%$ of them majored in business, event, or marketing management, while the remaining $40 \%$ focused on social science, arts, applied science, and language. The discussion included questions regarding the challenges instructors encounter in online teaching during the COVID-19 pandemic, the measures they have adopted, and their recommendations regarding student-toinstructor and student-to-student interactions. Meanwhile, the students were asked about the challenges they face in online learning during the pandemic, the methods they have used, and their suggestions for student-to-instructor and student-to-student interactions. The number of interviews that needed to be conducted depended on the point of saturation; that is, the whole process could be stopped when a researcher has found that most of the information has been gathered through multiple interviews.

\section{Findings}

Challenges to student-to-instructor interactions include (1) feedback, reactions, and clarifications; (2) recognition of students' participation; and (3) social presence and other factors while roadblocks to student-to-student interactions are (1) teamwork, (2) learning from peers, and (3) social presence.

\section{Challenges to student-to-instructor interactions}

\section{Feedback, reactions, and clarifications}

The participants reported their perceived challenges to student-to-instructor interactions based on their recent experience of participating in online classrooms (Fig. 1). The student participants were reluctant to directly and openly share their views in online classrooms. Specifically, they mentioned that online classrooms create restrictions 


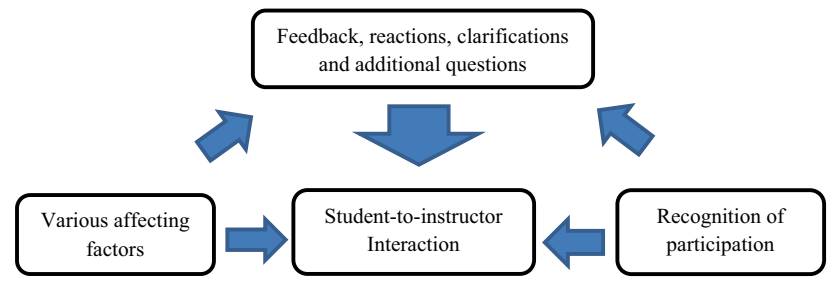

Fig. 1 Challenges hindering student-to-instructor interactions in online classrooms

for providing feedback, posting additional questions, and requesting clarifications on issues. Representative student comments included the following:

Unlike face-to-face meetings, the distance between lecture and students makes it harder for asking questions. (Male, Applied Science)

If everyone opens the microphone to ask questions, it would be noisy. One time I ask a question in the chatroom, but at the same time many students replied OK, it turned out that the teacher overlooked my question. (Female, Business/Marketing).

During face-to-face lectures, I can verbally raise questions immediately after class. Now, I have to think about how to put my questions in e-mails or deliberately make appointments with teachers. (Female, Business/Marketing).

Meanwhile, the interviewee instructors also shared similar sentiments regarding this major concern. Specifically, they reported that online classrooms create difficulties that hinder the understanding of students' learning outcomes through feedback and other virtual cues. For example, one participant stated that the:

Lecturer may feel more tired as they need to keep talking to fill up the virtual space or else it may appear dead air. In face-to-face classes, lecturers can make use of other senses and body gestures and manipulation of teaching facilities/tools to introduce more dynamics to classes even at the time of waiting for students' responses to questions. (Female, Business/Marketing, with More Than 10 Years of Teaching Experience).

\section{Recognition of students' participation}

The instructors also generally struggled in recognizing their students' participation, which prevents effective interactions between instructors and students, particularly in situations where students feel reluctant to turn on their microphones and cameras. Some typical comments of the interviewee instructors included the following:
You cannot guarantee students are really with you on the lesson. Students may just physically attend the lesson (while in fact doing something else)...it is more difficult to ask the students to interact with the teacher (as they can choose to hide their face and voice over the online learning platform). (Female, Business/Marketing, with More Than 10 Years of Teaching Experience).

Sometimes I used online name picker app to call specific students to answer my questions; they did not respond to me despite their names are shown as active online. I guess either they feel shy or they are actually not in front of the computer at that moment. (Male, Business/Marketing, with More Than 10 Years of Teaching Experience).

Unable to observe students' facial expressions and reactions making it harder to gauge their understanding and in turn decide whether I need to teach at a different pace. I am also unable to judge if they are really attending my lecture. (Female, Social Science, with 5-10 Years of Teaching Experience).

\section{Social presence and other factors}

According to the interview findings, various factors affect student-to-instructor interactions. The first is class size. Smaller sized classes can facilitate better student interactions with instructors and other classmates than classes with a larger number of students. One student stated that "in big classes, usually only the same few students talking in the class. By contrast, small classes of around 10 people could arouse more intense discussions since teachers can call students' names one by one, and ask them to participate" (Female, Social Science). The second factor is students' and instructors' online experience. Since different institutions and schools had to rapidly shift to online classrooms because of the worldwide spread of COVID-19, people just lack the experience and training in dealing with online classrooms. One student mentioned that "teachers and students need time to familiarize with the online learning system, as we have never used this kind of software in the past" (Female, Business/Marketing). Another student concurred, saying, "Not all teachers are familiar with the functions for calendar and assignment functions as we may expect; in such case, students still have to refer to Moodle for information viewing" (Male, Arts). The third factor pertains to students' personality, which may also restrict their online behaviors and interactions with their instructors. Students may hesitate to ask questions and provide feedback on public platforms. For example, a student said that in typical sharing activities, "I am shy to ask questions online, because I worry if I make typos, everyone would see it. In physical class, I often ask 
questions after class" (Female, Business/Marketing). This means that this particular student's awareness is rather low, and the instructor may pay less attention to them, which limits social presence and is not effective for online exchange under the aforementioned situation. According to social presence theory, information sharing would be restricted if communication quality is low.

\section{Challenges to student-to-student interactions}

\section{Teamwork}

Compared with instructors, the student participants expressed more concern regarding the lack of interactions with their peer students/classmates (Fig. 2). Consolidating inputs from the interviewee students and instructors, the study identified the online management of students' group projects as one major issue. Group projects constitute a certain percentage of a subject's score under continuous assessment. To effectively conduct group projects, students within a group need to discuss among themselves and show active support, which includes giving timely feedback and contributing to the preparation for the project's selected topics, preparing written reports and oral presentations, and so on. However, certain challenges have limited the effectiveness of such interactions.

Some student participants described and compared the technical and functional aspects of different online classroom platforms such as Microsoft Teams and Zoom. For example, one participant stated that:

I have used Zoom and Teams, comparing the two, Zoom provides voting and "small room" function, so that teachers need not to create another link for voting, and the latter is useful for small-group discussion during class, enabling teacher to conveniently divide students into subgroups. These functions make Zoom more efficient as an online learning tool than Teams. (Female, Social Science).

Most of the student participants agreed that using online classrooms with distant learning threatens efficient communication among group members, particularly with members

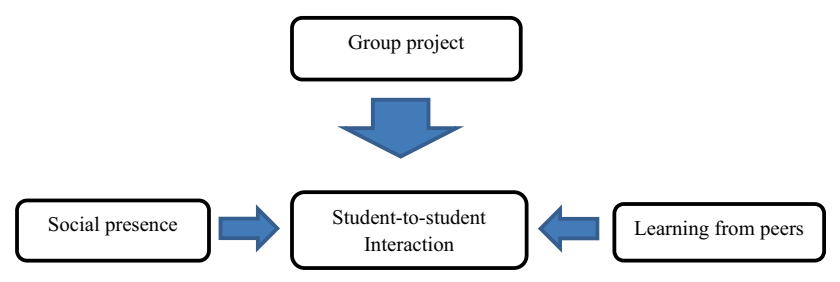

Fig. 2 Challenges hindering student-to-student interactions in online classrooms who are unfamiliar with one another. Some participants also expressed their apprehensions regarding the difficulty of obtaining even the basic contact information of their fellow students. Even group members who have previously collaborated may not easily meet and do not have timely and in-depth communications and discussions as opposed to normal classroom sessions. Representative comments from the student participants were as follows:

One extreme case I have encountered during this semester, there is a groupmate whom I do not know, I have to obtain that person's contact number from my teacher, but it was hurry because the project had already begun. (Female, Business/Marketing).

When doing group project, we may cooperate with classmates whom we are less familiar with. The only problem of using WhatsApp as the key communication means is slower interactions. (Female, Social Science). Online is not that good; in the past, we know each other before working together on group assignment. Now, we have to communicate using online means, texting for example, making it inconvenient for discussion. (Female, Business/Marketing).

This particular barrier to student-to-student interactions is also perceived as closely related to dissimilar levels of group members' self-motivation in joining and participating in online classrooms:

In the past when I have to leave home for school, the motivation is greater. When we are using Microsoft Teams to do project discussion, if certain teammate did not join us online, there is not much thing we can do; unlike in traditional settings, we can force him/her to discuss and listen to us. (Male, Applied Science).

The interviewed instructors also mentioned the lack of effective student-to-student interactions and discussions in online classrooms. In particular, they have no solid evidence to confirm whether their students are actively participating in the virtual discussions. One teacher stated that "instructors are not sure if students are really discussing with one another" (Female, Social Science, with 5-10 Years of Teaching Experience). Similarly, another instructor said that "group discussion and presentation are less effective in online classrooms" (Male, Natural Science, with More Than 10 Years of Teaching Experience). One instructor even provided specific challenges surrounding group project preparation:

Group project formation is more demanding or will take longer time than other activities as students do not see each other face-to-face but need get mutual support. Students tended to use chats only and their interaction is mostly limited to text only, and thus unable to 
use other senses to feel the presence or responses from other classmates. They may want to respond or laugh or to show support or encouragement as if they meet physically, but all these body gestures are not effective or even absent for online discussion. (Female, Business/Marketing, with More Than 10 Years of Teaching Experience).

\section{Peer learning}

Besides group project discussions, learning from peers in general is considered extremely important in the student learning process. In normal classroom settings, students may approach their instructors and peers to figure out possible answers to their questions or viable solutions to different challenges or obstacles to their learning. However, one student participant commented that such a situation is hardly achieved in online classrooms:

Students tend not to ask questions in online class; they prefer asking friends or try to find solutions by themselves. In this case, their queries and doubts may not be addressed immediately and get clarified by teachers. (Female, Business/Marketing).

\section{Social presence}

Under normal circumstances, since students are at an active learning stage, they look for some awareness of or social presence in their learning environment, even in online classrooms. Students need clear social positions and identities relative to other students. They may wish to join different on- and off-campus activities and have intense interactions with other students or within their community. These social needs contribute to students' learning experiences and satisfaction. However, the student participants identified the different challenges they are facing:

In some cases, I have never met some of the groupmates even after the end of the semester. It has never happened in the past, as we will schedule activities like having meals and drinks together after school and have more frequent social interactions. (Female, Business/ Marketing).

Microsoft Teams is convenient for us to chat without the need of fixing schedule with classmates like when we go to school, but we no longer can have celebration meals after projects are completed as what we did in the past. (Female, Business/Marketing).

Social presence theory states that establishing cognitive social presence is quite difficult, as it requires a relatively longer time and more frequent and intensive social interactions. For example, students like to go to the library to study together, and they also need social activities such as hanging out or shopping. Moreover, affective social presence cannot be fully established, as some students hide from online lessons by not turning on or facing their cameras or are even altogether absent in live sessions. Some students prefer watching recorded lessons only.

\section{Recommendations for interactions}

Because the interviewed instructors have substantial teaching experience, they were also asked to share their successful teaching efforts and propose recommendations regarding the facilitation of student interactions with instructors and other students in online classrooms. Recommendation themes for facilitating students' exchanges with instructors appear similar with those provided for their interactions with their peers. For example, this study found that encouragement, incentives, breakout rooms, and various techniques were effective in facilitating and managing both kinds of interactions. The uniqueness of the two interaction types also leads to different recommendations that can be used to manage students' and instructors' perceived challenges. More consultations or even tailor-made discussions can facilitate student-to-instructor interactions, whereas peer evaluation can be used professionally and effectively to enhance quality student-to-student exchange, particularly in their collaboration and preparation of group project assessments. Figure 3 provides an overall diagram of the recommendation themes. Table 2 shows the details of specific recommendations, including productive efforts by the interviewed instructors in handling the traditional or online classes. These recommendations can be adopted as direct guidance and advice for instructors.

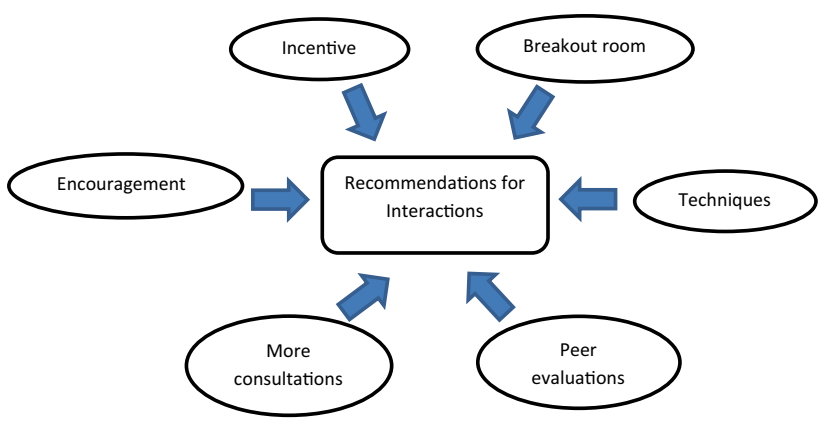

Fig. 3 Recommendations for the facilitation of student interactions in online classroom settings 


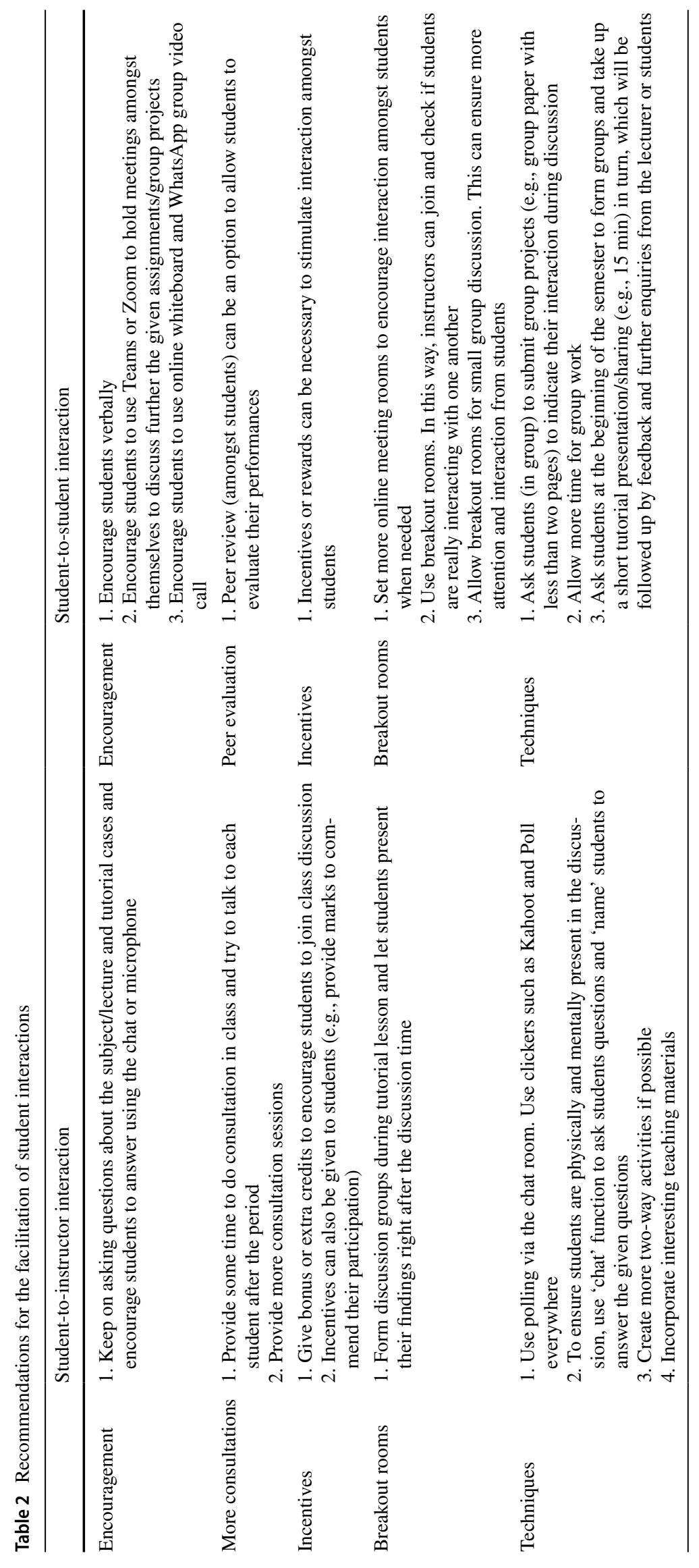




\section{Discussion}

While online education and online classroom management have been popular topics ( $\mathrm{Li}$ and Beverly 2008; Palvia et al. 2018), practitioners have been unprepared for changes in teaching methods until the COVID-19 pandemic (Hodges et al. 2018). Focusing on higher education, this empirical research addresses the existing research gaps by tapping further into person-to-person interactions in the online classroom context. Although coverage from prior studies in this area had been scarce (Jung et al. 2002; Kuo et al. 2014), a summary of consolidated views from instructors and students could still provide insights into the understanding of focal concepts and practices in student online learning.

This study exemplifies Moore's (1989) theoretical framework by focusing on person-to-person exchanges in online education, particularly student-to-instructor and student-to-student interactions. It successfully answered two research questions. To address the first research question, Figs. 1 and 2 summarize the challenges perceived by instructors and students. This partially mirrors the results of Popovich and Neel (2005), who identified the disadvantages and challenges to online education. This study observed that instructors appeared to be more concerned about challenges surrounding their interactions with students, whereas students focus more on their interactions with their peers. This is a clear deviation from Kuo et al.'s (2014) finding that students feel unimportant in their interactions with peers. Given the nature of synchronous and asynchronous communications and learning types in the online learning context (Bernard et al. 2009) and other different influential barriers (i.e., class size, personality, and online experience), distance is perceived between students and their instructors and peers. Not only do instructors experience hardship in maintaining and enhancing students' motivation and participation; students also perceive difficulties in asking questions and obtaining efficient feedback as well as coordinating among teammates in group project preparations in online education. Students expect effective familiarization and discussion with other groupmates in the online context and expect their peers to participate and contribute reasonably to group projects. Similarly, the instructors also believe that student-to-student discussion is also critical to students' study process. This is particularly important when group assessments form part of the course requirements (Jung et al. 2002). However, students may feel disappointed, since they obtain extremely limited output from their peers, which is a substantial deviation from their expectations. Other types of peer interactions, as rooted in the "social presence" phenomenon (Gunawardena and Zittle 1997), were also found ineffective and lacking to a certain extent. The situation even worsened as the scoring proportion from group project assessments increased and took the place of other components such as examinations or tests. Some universities have replaced examinations by giving students more individual assignments during the outbreak of COVID-19. In the past, students would have also liked to obtain peer feedback and brainstorm ideas and even work on individual assignments. Ineffective peer learning under the circumstances of the COVID-19 pandemic would probably impair online learning results.

Finally, this study extends the existing body of knowledge on social presence theory with a discussion of personto-person interactions in an online classroom context. The awareness (Chang and Hus 2016) of student identity and the exchange of viewpoints are clearly more challenging among students or between students and instructors. Both cognitive and affective social presence (Shen and Khalifa 2008) were found to be crucial; the people involved need to understand the meanings behind their relationships and obtain mutual mental support, so that students can realize changes in the new facet of their college lives under the circumstances and find ways to enhance their learning effectiveness while participating in virtual classes.

\section{Practical implications}

Drawing on the interviewed instructors' input, this study provides valid recommendations for facilitating and managing both types of person-to-person interactions in online learning, thus addressing the second research question. The management systems of different universities and institutions in other countries and locations can also focus on these recommendations and use them as direct guidance when setting standards for instructors handling online classroom management and teaching under the impact of COVID-19. Moreover, management has to encourage their instructors to enhance their skills and knowledge in online education more strategically to encourage their students to adapt to a new learning life; management also has to focus on evaluating the instructors' performance in fulfilling such an objective. Instructors' ability to manage online classroom settings can be fully reflected in students' feedback. For example, instructors must always encourage their students to maintain active interactions with them and with other classmates through different channels. Instructors are also advised to develop assessment rubrics to evaluate student interaction performance. They must also provide additional marks to further motivate student interaction whereas peer evaluations must be conducted to assess group projects. More university resources must be allocated to develop other direct techniques and measures for student interactions because 
of COVID-19. IT support and advice (e.g., how to set up breakout rooms) are also critical in helping and training instructors and students to accumulate and upgrade their online teaching and learning experience. Maguire (2005) highlighted the significance of institutional support as either motivators or inhibitors for online education. This needs a particular attention for sustainable online education, so that experiences and existing lessons could pave the way to prepare for the future (Palvia et al. 2018).

Second, management must also consider flexibility in policy implementation. Universities must be adaptable in the decision-making and establishment of policies to address different crises and emergencies, such as setting up standard operating procedures to provide instructors guidance on choosing the most suitable teaching modes, including online teaching or hybrid teaching, which integrates both online and face-to-face teaching, and consider other criteria such as class size, year of study, and subject nature, among others, to quickly react and respond to different situations or crises. It is understood that the COVID-19 epidemic may not be a short-term crisis, and management should also prepare for other emergencies such as the social unrest in Hong Kong in 2019, which might affect normal teaching and need preparations for adapting to a partially or fully online classroom arrangement (Crawford et al. 2020). Indeed, the sustainability of effective communication and feedback system among instructors and students is crucial at a policy level.

The third recommendation pertains to privacy issues. Recorded sessions are usually posted online for students' viewing, but some of the comments have indicated a concern that this would expose the classes to the general public, since the students and other authorized persons within the faculty can access them directly; thus, it would be challenging to prohibit and control the inappropriate sharing of such videos with other outsiders. In addition, some groups of people, while in online classrooms, may be sensitive to privacy issues and, therefore, become hesitant to participate actively by speaking online and showing their faces. This creates a dilemma in which person-to-person interaction is impeded by privacy considerations. Meanwhile, instructors may also be apprehensive about disclosing students' identity directly, while the class is conducted online with a video recording. Direct compliments or comments relating to specific students may be considered inappropriate when privacy issues are a concern.

\section{Conclusion}

This study sought to investigate person-to-person interactions in online classrooms from a social presence theory perspective. It found that teachers experience difficulties in recognizing student participation in a detailed manner under the circumstances of COVID-19. They might be aware of their students' presence, but they lack an in-depth understanding of whether these students can fully grasp the core issues of the learning topics. Awareness, from a social presence theory perspective, needs to be enhanced. Other factors such as class size, online experiences, and personality could also affect the effectiveness of online classrooms. Additionally, informal feedback and clarifications are also absent in online classrooms.

Regarding challenges to student-to-student interactions in group projects or other academic activities, learning from peers is quite difficult in online classroom settings. In the traditional classrooms, students can directly discuss with fellow classmates to obtain insights, ideas, and suggestions, but not in online settings. Cognitive social presence and affective social presence shed light on such a phenomenon.

With the COVID-19 outbreak and a possible economic downturn in the near future, people are facing tough times and need to be more resilient to get through these difficulties. The same is true for instructors and students; they have to undergo rapid changes and adapt to a new teaching and learning lifestyle as well as quickly respond to certain incidents. This study revealed the different challenges faced by instructors and students regarding person-to-person interactions in online classrooms, and provides recommendations such as encouragement, incentives, consultations, peer evaluation, breakout rooms, and other techniques to enhance the online learning experience. Because of limitations to the research timeline, only 24 interviews were successfully conducted with college students and instructors. However, primary and secondary schools as well as kindergartens also face difficulties that may or may not be similar to the ones mentioned in this study. Thus, future studies may be extended to cover these areas and make necessary comparisons. Scholars would be prudent to conduct a cross-cultural study that compares the reported challenges in different places and countries in the world, given the understanding that online classrooms may not be the only solution pertaining to social distancing. Online classrooms may also serve as a future student learning trend. All related education topics that might arise from or relate to this trend can be considered as future research opportunities. Topics such as teaching quality, education environment, curriculum design, student satisfaction and experience, faculty development, privacy and ethical issues, and policy implementation can all be included in future research agenda.

\section{References}

Abrami, P., Benrnard, R. M., Bures, Ev., Borokovski, E., \& Tamim, R. (2011). Interaction in distance education and online learning: 
Using evidence and theory to improve practice. Journal of Computing in Higher Education, 23(2), 82-103.

Anderson, T. (2003). Getting the mix right again: An updated and theoretical rationale for interaction. International Review of Research in Open and Distance Learning, 4(2), 9-14.

Bao, W. (2020). COVID-19 and online teaching in higher education: A case study of Peking University. Human Behavior and Emerging Technologies, 2, 113-115.

Basilaia, G., \& Kvavadze, D. (2020). Transition to online education in schools during a SARS-CoV-2 Coronavirus (COVID-19) pandemic in Georgia. Pedagogical Research, 5(4), 1-9.

Bernard, R. M., Abrami, P. C., Borokhovski, E., Wade, C. A., Tamim, R. M., Surkes, M. A., \& Bethel, E. C. (2009). A meta-analysis of three types of interaction treatments in distance education. Review of Educational Research, 79(3), 1243-1289.

Bolliger, D. U., \& Martindale, T. (2004). Key factors for determining student satisfaction in online courses. International Journal on E-Learning, 3(1), 61-67.

Brooks, S.K., Webster, R.K., Smith, L.E., Woodland, L., Wessely, S., \& Greenberg, N. etal. (2020). The psychological impact of quarantine and how to reduce it: rapid review of the evidence. The Lancet: Rapid Review. Retrieved from: https://www.thelancet. com/journals/lancet/article/PIIS0140-6736(20)30460-8/fulltext

Chang, C., \& Hsu, M. (2016). Understanding the determinants of users' subjective well-being in social networking sites: An integration of social capital theory and social presence theory. Behaviour \& Information Technology, 35(9), 720-729.

Cheung, T. (2020). Coronavirus crisis to hit economies worldwide, Hong Kong finance chief warns, citing downgraded analyst forecasts. South China Morning Post. Retrieved March 8, 2020, from https://www.scmp.com/news/hong-kong/hong-kong-econo my/article/3074134/coronavirus-crisis-hit-economies-world wide-hong

Coll, C., Rochera, M. J., \& de Gispert, I. (2014). Supporting online collaborative learning in small groups: Teacher feedback on learning content, academic task and social participation. Computers \& Education, 75, 53-64.

Crawford, J., Butler-Henderson, K., Rudolph, J., Malkawi, B., Glowatz, M., Burton, R., et al. (2020). COVID-19: 20 countries' higher education intra-period digital pedagogy responses. Journal of Applied Learning \& Teaching, 3(1), 9-28.

Flick, U. (2014). An introduction to qualitative research (5th ed.). Thousand Oaks, CA: Sage.

Gefen, D., \& Straub, D. W. (2004). Consumer trust in B2C e-Commerce and the importance of social presence: Experiments in e-products and e-services. Omega, 32, 407-424.

Goh, P. S., \& Sandars, J. (2020). A vision of the use of technology in medical education after the COVID-19 pandemic. MedEdPublish, 26.

Gonzalez, T., de la Rubia, M. A., Hincz, K. P., Comas-Lopez, M., Subirats, L., Fort, S., et al. (2020). Influence of COVID-19 confinement on students' performance in higher education. PLOS ONE, 15(10), e0239490.

Gunawardena, C., \& Zittle, F. (1997). Social presence as a predictor of satisfaction within a computer mediated conferencing environment. American Journal of Distance Education, 11, 8-26.

Hodges, C., Moore, S., Lockee, B., Trust, T., \& Bond, A. (2020). The difference between emergency remote teaching and online learning. Educausereview. Retrieved March 27, 2020, from https:// er.educause.edu/articles/2020/3/the-difference-between-emerg ency-remote-teaching-and-online-learning.

Hrastinski, S. (2008). What is online learner participation? A literature review. Computers \& Education, 51, 1755-1765.

Iyer, P., Aziz, K., \& Ojcius, D. M. (2020). Impact of COVID-19 on dental education in the United States. Journal of Dental Education, 84(6), 718-722.
Jung, I., Choi, S., Lim, C., \& Leem, J. (2002). Effects of different types of interaction on learning achievement, satisfaction and participation in web-based instruction. Innovations in Education \& Teaching International, 39(2), 153-162.

Keengwe, J., \& Kidd, T. T. (2010). Towards best practices in online learning and teaching in higher education. MERLOT Journal of Online Learning and Teaching, 6(2), 533-541.

Kumar, R. (2005). Research methodology. London: Sage.

Kuo, Y. C., Walker, A. E., Schroder, K. E. E., \& Belland, B. R. (2014). Interaction, internet self-efficacy, and self-regulated learning as predictors of student satisfaction in online education courses. Internet and Higher Education, 20, 35-50.

Lau, H., Khosrawipour, V., Kocbach, P., Mikolajczyk, A., Ichii, H., Zacharksi, M., et al. (2020). The association between international and domestic air traffic and the coronavirus (COVID-19) outbreak. Journal of Microbiology, Immunology and Infection, 53, 467-472.

Li, C. S., \& Beverly, I. (2008). An overview of online education: Attractiveness, benefits, challenges, concerns and recommendations. College Student Journal, 42(2, Part A), 449-458.

Maguire, L. L. (2005). Literature review-faculty participation in online distance education: barriers and motivators. Online Journal of Distance Learning Administration.

Moore, M. G. (1989). Three types of interaction. American Journal of Distance Education, 3(2), 1-6.

Morawska, L., \& Cao, J. (2020). Airborne transmission of SARSCoV-2: The world should face the reality. Environment International, 105730.

$\mathrm{Ni}$, A. Y. (2018). Comparing the effectiveness of classroom and online learning: Teaching research methods. Journal of Public Affairs Education, 19(2), 199-215.

Nkonge, B., \& Geuldenzolph, L. (2006). Best practices in online education: Implications for policy and practice. Business Education Digest, 15, 42-53.

Our World in Data. (2020, July 15). Stay-at-home requirements during the COVID-19 pandemic. Our World in Data. Retrieved from: https://ourworldindata.org/grapher/stay-at-home-covid

Palvia, S., Aeron, P., Gupta, P., Mahapatra, D., Parida, R., Rosner, R., \& Sindhi, S. (2018). Online education: Worldwide status, challenges, trends, and implications. Journal of Global Information Technology Management, 21(4), 233-241.

Picciano, A. (1998). Developing an asynchronous course model at a large, urban university. Journal of Asynchronous Learning Networks, 2.

Popovich, C. J., \& Neel, R. E. (2005). Characteristics of distance education programs at accredited business schools. American Journal of Distance Education, 19, 229-240.

Salcedo, A., Yar, S., \& Cherelus, G. (2020, July 11). Coronavirus Travel Restrictions, Across the Globe. New York Times. Retrieved from: https://www.nytimes.com/article/coronavirus-travel-restr ictions.html

Shen, K. N., Yu, A. Y., \& Khalifa, K. (2010). Knowledge contribution in virtual communities: Accounting for multiple dimensions of social presence through social identity. Behaviour \& Information Technology, 29(4), 337-348.

Shim, H. (2020, June 11). Seoul unveils roadmap to make "K-quarantine" global standard. Korean Biomedical Review. Retrieved from: http://www.koreabiomed.com/news/articleView.html?idxno $=8479$

Short, J., Williams, E., \& Christie, B. (1976). The social psychology of telecommunications. London: Wiley.

Sobaih, A. E. E., Hasanein, A. M., \& Abu Elnasr, A. E. (2020). Responses to COVID-19 in higher education: Social media usage for sustaining formal academic communication in developing countries. Sustainability, 12, 6520.

Sohrabi, C., Alsafi, Z., O’Neill, N., Khan, M., Kerwan, A., Al-Jabir, A., et al. (2020). World Health Organization declares global 
emergency: A review of the 2019 novel coronavirus (COVID19). International Journal of Surgery, 76, 71-76.

Swan, K. (2002). Building learning communities in online courses: The importance of interaction. Education, Communication \& Information, 2(1), 23-49.

Toquero, C. (2020). Challenges and opportunities for higher education amid the COVID-19 pandemic: The Philippine Context. Pedagogical Research, 5(4), 1-5.

Van Lancker, W., \& Parolin, Z. (2020). COVID-19, school closures, and child poverty: a social crisis in the making. The Lancet Public Health, 5(5), e243-e244.

Weaver, C. M., \& Albion, P. (2005). Momentum in online discussions: the effect of social presence on motivation for participation. In: ASCILITE 2005: 22nd Annual Conference of the Australasian Society for Computers in Learning in Tertiary Education: Balance, Fidelity, Mobility - Maintaining the Momentum? 4-7 Dec 2005, Brisbane, Australia.
WHO. (2020, July 14) Coronavirus disease (COVID-2019) Situation Report-176. World Health Organization. Retrieved from: https ://www.who.int/emergencies/diseases/novel-coronavirus-2019/ situation-reports

Zhang, W., Wang, Y., Yang, L., \& Wang, C. (2020). Suspending classes without stopping learning: China's education emergency management policy in the COVID-19 outbreak. Journal of Risk Financial Management, 13(3), 55.

Publisher's Note Springer Nature remains neutral with regard to jurisdictional claims in published maps and institutional affiliations. 